\title{
A Common Ground Switched-Quasi-Z-Source Bidirectional DC-DC Converter with Wide-Voltage-Gain Range for EVs with Hybrid Energy Sources
}

Yun Zhang, Member, IEEE, Qiangqiang Liu, Jing Li, Member, IEEE, and Mark Sumner, Senior Member, IEEE

\begin{abstract}
A common ground switched-quasi-Z-source bidirectional DC-DC converter is proposed for electric vehicles (EVs) with hybrid energy sources. The proposed converter is based on the traditional two-level quasi-Z-source bidirectional DC-DC converter, changing the position of the main power switch. It has the advantages of a wide voltage gain range, a lower voltage stress across the power switches, and an absolute common ground. The operating principle, the voltage and current stresses on the power switches, the comparisons with the other converters, the small signal analysis and the controller design are presented in this paper. Finally, a $300 \mathrm{~W}$ prototype with $U_{\text {high }}=240 \mathrm{~V}$ and $U_{\text {low }}=40 \sim 120 \mathrm{~V}$ is developed, and the experimental results validate the performance and the feasibility of the proposed converter.
\end{abstract}

Index Terms-Bidirectional DC-DC converter, common ground, EVs, hybrid energy sources, switched-quasi-Z-source, wide voltage gain range.

\section{INTRODUCTION}

With the increase of per capita car ownership in the world, the increases in fossil fuel consumption and greenhouse gas emission are having a serious effect on the climate and environment [1]-[5]. New energy vehicles with renewable energy as the power source, which can achieve operation with zero pollution emissions, are considered as one of the solutions to effectively alleviate the energy crisis and the environmental pollution associated with transportation [6], [7]. As one of the most important "new energy" vehicles, electric vehicles with hybrid energy sources mainly comprise high energy density power batteries and high power density super capacitors. The low-voltage batteries are used to maintain the high voltage of the DC bus during steady-state, even when the required energy has low-frequency fluctuations. The super capacitors can be used to provide or absorb high-frequency instantaneous power during the electric vehicle's accelerating or braking process. Thus, these two hybrid energy sources can greatly reduce the

Manuscript received May 30, 2017; revised August 22, 2017; accepted September 7, 2017. This work was supported in part by the National Natural Science Foundation of China under Grant 51577130, and in part by the Research Program of Application Foundation and Advanced Technology of Tianjin China under Grant 15JCQNJC03900.

Y. Zhang, Q. Liu are with the School of Electrical and Information Engineering, Tianjin University, Nankai, Tianjin, China (e-mail: zhangy@tju.edu.cn; lqqcumt@163.com).

$\mathrm{J}$. Li is with the Department of Electrical and Electronic Engineering, University of Nottingham Ningbo China, Ningbo, China (e-mail: Jing.Li@nottingham.edu.cn).

M. Sumner is with the Department of Electrical and Electronic Engineering, University of Nottingham, Nottingham, England, U.K (e-mail: mark.sumner@nottingham.ac.uk). degradation impact on the power batteries caused by the sudden load change of the electric vehicle, and also improve the dynamic response of the whole powertrain system [8], [9].

The voltage level of hybrid energy sources for electric vehicles is relatively low. In order to realize the matching of the voltage levels between the hybrid energy sources and the high voltage DC bus, as well as the bidirectional power flow of energy sources, a wide voltage-gain range bidirectional DC-DC converter is needed to interface the energy sources and the DC bus.

With regard to the wide voltage-gain range bidirectional DC-DC converter, basically, it can be classified into two categories: isolated and non-isolated. The isolated types of bidirectional converters include Fly-back converters, forward converters, half-bridge and full-bridge bidirectional converters. One of the advantages of these bidirectional DC-DC converters is that they have a wide voltage-gain range in the step-up and step-down modes. Although the Fly-back converter has a simple structure and can be controlled easily, the leakage inductor loss caused by the high frequency transformer mean the converter has a low efficiency. In addition, the leakage inductor causes high voltage spikes, which means the power switches see a high voltage stress.

Non-isolated bidirectional converters include conventional two-level converters and multilevel converters, Cuk/Sepic/Zeta converters, coupled-inductor converters, switched-capacitor and switched-inductor converters, Z-source and quasi-Z-source converters. The conventional two-level converters have a high voltage stress on the power switches, a narrow voltage-gain range, and their efficiencies and dynamic responses are limited by the extreme duty cycles of the power switches. Therefore, they are not suitable for the hybrid energy sources system of electric vehicles. As to the three-level DC-DC converters, although the voltage stress on the power switches is significantly reduced, the practical voltage gain in the step-up and step-down modes is relatively low due to the parasitic parameters [10], [11]. Multi-level DC-DC converters have a wide voltage gain range, but they need more power switches, other additional hardware circuits and a control strategy to maintain the balance of the voltage stress on the power switches [12]. Although the voltage gain range of the Cuk/Sepic/Zeta converters is wider, the cascaded structures limit the conversion efficiency [13]-[15]. Coupled-inductor DC-DC converters can achieve a high voltage gain by adjusting the turns ratio of the coupled inductor, but they require more power switches and need to address the problem of the leakage inductance, which make their structure more complex. In addition, the power conversion and transmission capability of the converter is also limited by the performance of the coupled inductor [16]-[18]. 
The structures and control schemes of the Z-source, the quasi-Z-source and the switched-capacitor DC-DC converters are simple and easy to expand, and the capacitors in these converters deliver energy through different paths during the charge and the discharge processes. Thus, a high voltage gain can be achieved [19]-[22]. Switched-inductor bidirectional DC-DC converters can also achieve a wide voltage gain range and a low voltage stress while avoiding extreme duty cycles. However, more inductors limit the power density [23], [24].

A new non-isolated single capacitor bidirectional DC-DC converter is presented in [25]. Although it has a wide voltage gain range, the voltage stress on the power switches is relatively high. In [22], a switched-capacitor-based DC-DC converter is proposed. Although the voltage gain is improved, more devices are used, and the converter does not have a common ground. A bidirectional switched-capacitor DC-DC converter is presented in [26]. This converter improves the efficiency, but the converter needs more power switches. A hybrid bidirectional converter with a switched-capacitor cell, which is suitable for a DC microgrid, is proposed in [27]. It has a wider voltage gain range and lower power voltage stress across the power switches, but the converter does not have an absolute common ground between the input and output sides, which produces an additional $\mathrm{d} u / \mathrm{d} t$ issue between the input and output grounds. Thus, its applications are limited. In [28], a novel coupledinductor bidirectional DC-DC converter is proposed with increased voltage gain. However, the leakage inductance of the coupled inductor and the additional $\mathrm{d} u / \mathrm{d} t$ problems between the input and output grounds should be considered additionally, and the voltage stress on the power switches that are near the high voltage side is too high.

This paper presents a novel switched-quasi-Z-source bidirectional DC-DC converter for EVs with hybrid energy sources, which not only achieves a wide voltage gain range, but also has a common ground. The proposed converter is based on the traditional two-level quasi-Z-source bidirectional DC-DC converter: it simply changes the position of the main power switch. As well as a wide voltage gain range and a low voltage stress on power switches, this converter also has a simple structure. As a result, the proposed converter can select the power switches with the low rated voltage, and the low on-state resistance, which in turn can improve the conversion efficiency. Simultaneously, the voltage-gain of the proposed converter is just reduced a bit, which can still meet the requirement of the application of EVs with hybrid energy sources. The absolutely common ground also avoids the additional $\mathrm{d} u / \mathrm{d} t$ issue between the input and output grounds, which is beneficial for the operation of the proposed converter.

The structure of the paper is organized as follows. Section II introduces the configuration of the proposed converter and analyzes the operating principle in detail. The design and analysis of the converter are given in Section III. The experimental results and analysis are shown in Section IV. Finally, Section V presents conclusions.

\section{OPERATING PrinCiPle AND ANALYSIS OF THE PROPOSED CONVERTER}

\section{A. Configuration of the Proposed Converter}

The configuration of the proposed bidirectional DC-DC converter is shown in Fig.1. It can be seen that the proposed converter consists of a switched-quasi-Z-source network $\left(L_{1}, L_{2}\right.$, $C_{1}, C_{2}$ and $Q_{2}$ ), power switches $Q_{1}$ and $Q_{3}$, and high/low voltage side energy storage/filter capacitors $C_{\text {high }}$ and $C_{\text {low }}$. The gate signals $S_{2}$ and $S_{3}$ of the power switches $Q_{2}$ and $Q_{3}$ are identical, and they are complementary to the gate signal $S_{1}$ of $Q_{1}$. The proposed converter can operate either in the step-up or in the step-down mode, enabling the bidirectional power flow between the high-voltage and low-voltage sides.

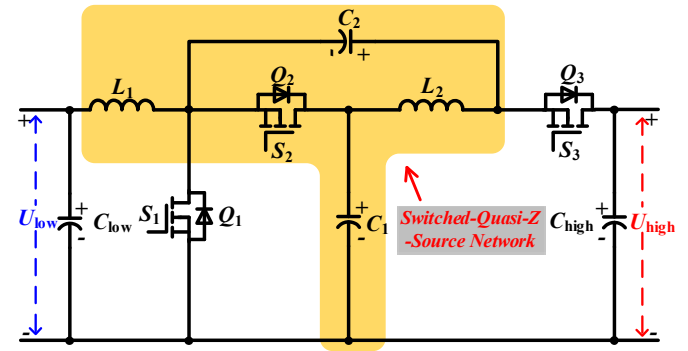

Fig.1 Configuration of the proposed converter.

\section{B. Operating Principle of the Proposed Converter}

To simplify the analysis, the following assumptions are made.

1) All the components are ideal, ignoring the ON-STATE resistance $R_{\mathrm{DS}}$ (on) of the power switches and equivalent series resistance(ESR) of the inductors and capacitors.

2) The currents of the inductors and voltages of the capacitors increase and decrease linearly.

3) The voltages across capacitors are constant.
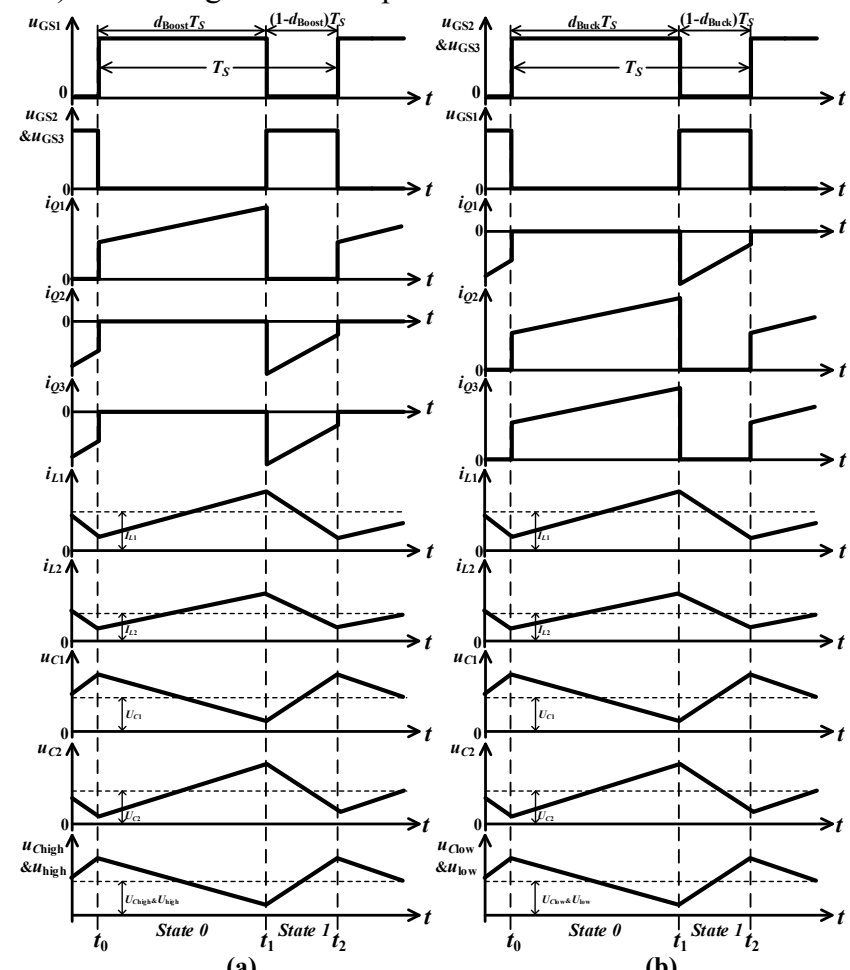

(b)

Fig.2 Typical waveforms of the proposed converter. (a) Step-up mode. (b) Step-down mode.

The two main operating modes of the proposed converter are given as follows:

Mode I. Step-Up Mode of the Proposed Converter 
When the proposed converter operates in the step-up mode, namely the energy flows from the low voltage side to the high voltage side. In this operating mode, $Q_{1}$ operates as a main power switch, and $Q_{2}$ and $Q_{3}$ are the synchronous rectifiers. The duty cycles of the gate signals $S_{1}, S_{2}$ and $S_{3}$ are taken as $d_{1}=1-d_{2}=$ $1-d_{3}=d_{\text {Boost }}$. The typical waveforms of the proposed converter in continuous conduction mode (CCM) are shown in Fig.2 (a), and the corresponding current flow paths in one switching period are illustrated in Fig.3 (a) and (b).

State $0\left[\boldsymbol{t}_{\mathbf{0}}-\boldsymbol{t}_{\mathbf{1}}\right]$ : When $S_{1} S_{2} S_{3}=100, Q_{1}$ is turned on, and $Q_{2}$ and $Q_{3}$ are turned off, the current flow paths are shown in Fig.3 (a). During this state, the inductor $L_{1}$ is charged by $U_{\text {low }}$ through $Q_{1}$, while the capacitor $C_{1}$ is discharged, and the energy is transferred to the capacitor $C_{2}$ and the inductor $L_{2}$ through $Q_{1}$. Capacitor $C_{\text {high }}$ is also discharged to supply the energy for the load $R_{\text {load Boost }}$ According to Fig.3 (a), the following equations can be derived in state 0 :

$$
\begin{aligned}
& \left\{\begin{array}{l}
U_{L 1}=U_{\text {low }} \\
U_{L 2}=U_{C 1}-U_{\mathrm{C} 2} \\
U_{\text {high }}=U_{C \text { high }}
\end{array}\right. \\
& \left\{\begin{array}{l}
i_{C 1 \_d_{\text {Boost }}}=-i_{L 2} \\
i_{C 2 \_d_{\text {Boost }}}=i_{L 2} \\
i_{C h i g h \_d} d_{\text {Boost }}=-I_{\text {high }}
\end{array}\right.
\end{aligned}
$$

State $1\left[\boldsymbol{t}_{\mathbf{1}}-\boldsymbol{t}_{\mathbf{2}}\right]$ : When $S_{1} S_{2} S_{3}=011, Q_{1}$ is turned off, and $Q_{2}$ and $Q_{3}$ are reversely turned on. The current flow paths are shown in Fig.3 (b). During this interval, the input voltage $U_{\text {low }}$ and the inductor $L_{1}$ charge the capacitor $C_{1}$ in series. The capacitor $C_{2}$ is connected in parallel with inductor $L_{2}$, then connected with $U_{\text {low }}$ and $L_{1}$ in series to charge the capacitor $C_{\text {high }}$ and provide the energy for the load. As a result, the output voltage $U_{\text {high }}$ is boosted up, and is much higher than the input voltage $U_{\text {low }}$. According to Fig.3 (b), the following equations can also be obtained in state 1 :

$$
\begin{gathered}
\left\{\begin{array}{l}
U_{L 1}=U_{\text {low }}-U_{C 1} \\
U_{L 2}=U_{C 1}-U_{C h i g h} \\
U_{C h i g h}=U_{C 2}+U_{C 1} \\
U_{\text {high }}=U_{C h i g h}
\end{array}\right. \\
\left\{\begin{array}{l}
i_{C 1 \_\left(1-d_{\text {Boost }}\right)}=i_{L 1}+i_{C 2 \_\left(1-d_{\text {Boost }}\right)}-i_{L 2} \\
i_{\text {Chigh_(1-d } \left.d_{\text {Boost }}\right)}=i_{L 2}-i_{C 2 \_\left(1-d_{\text {Boost }}\right)}-I_{\text {high }}
\end{array}\right.
\end{gathered}
$$

By applying the volt-second balance principle on inductors $L_{1}$ and $L_{2}$ with (1) and (3), the relationship between the voltage gain $M_{\text {Boost }}$ and the duty cycle $d_{\text {Boost }}$ in CCM can be obtained as

$$
M_{\text {Boost }}=\frac{1+d_{\text {Boost }}}{1-d_{\text {Boost }}}
$$

and the voltage stresses across the capacitors $C_{1}$ and $C_{2}$ can be expressed as

$$
\left\{\begin{array}{l}
U_{C 1}=\frac{U_{\text {low }}}{1-d_{\text {Boost }}}=\frac{U_{\text {high }}}{1+d_{\text {Boost }}} \\
U_{C 2}=\frac{d_{\text {Boost }} U_{\text {low }}}{1-d_{\text {Boost }}}=\frac{d_{\text {Boost }} U_{\text {high }}}{1+d_{\text {Boost }}}
\end{array}\right.
$$

By applying the ampere-second balance principle on capacitors with (2) and (4), the average inductor currents $I_{L 1}$ and $I_{L 2}$ can be obtained as

$$
\left\{\begin{array}{l}
I_{L 1}=\frac{1+d_{\text {Boost }}}{1-d_{\text {Boost }}} I_{\text {high }} \\
I_{L 2}=I_{\text {high }}
\end{array}\right.
$$

\section{Mode II. Step-Down Mode of the Proposed Converter}

When the proposed converter operates in the step-down mode, namely the energy flows from the high voltage side to the low voltage side. In this operating mode, $Q_{2}$ and $Q_{3}$ operate as the main power switches, and $Q_{1}$ is the synchronous rectifier. The duty cycles of the gate signals $S_{2}, S_{3}$ and $S_{1}$ are taken as $d_{2}=d_{3}=1-d_{1}=d_{\text {Buck }}$. The typical waveforms of the proposed converter in CCM are shown in Fig.2 (b), and the corresponding current flow paths in one switching period are illustrated in Fig.4 (a) and (b).

State 0 [ $\left.\boldsymbol{t}_{\mathbf{0}}-\boldsymbol{t}_{\mathbf{1}}\right]$ : When $S_{1} S_{2} S_{3}=011, Q_{1}$ is turned off, and $Q_{2}$ and $Q_{3}$ are turned on, the current flow paths are shown in Fig.4 (a). During this state, $L_{1}, L_{2}, C_{2}$, and the low voltage side load $R_{\text {load_Buck }}$ are charged by $U_{\text {high }}$ through $Q_{3}$ and $Q_{2}$, while $C_{1}$ is discharged for $L_{1}$ and $R_{\text {load_Buck }}$ through $Q_{2}$. Then, the following equations can be derived in state 0 :

$$
\begin{gathered}
\left\{\begin{array}{l}
U_{L 2}=U_{\text {high }}-U_{C 1} \\
U_{L 1}=U_{C 1}-U_{\text {low }} \\
U_{C 1}+U_{C 2}=U_{\text {high }} \\
U_{\text {high }}=U_{C 3}
\end{array}\right. \\
\left\{\begin{array}{l}
i_{C 1 \_d_{\text {Buck }}}=i_{C 2 \_d_{\text {Buck }}}-i_{L 1}+i_{L 2} \\
i_{C 2 \_d_{\text {Buck }}}=I_{\text {high }}-i_{C 3 \_d_{\text {Buck }}}-i_{L 2} \\
i_{L 1}=I_{\text {low }}+i_{C \text { low } \_d_{\text {Buck }}}
\end{array}\right.
\end{gathered}
$$

State 1 [ $\left.\boldsymbol{t}_{\mathbf{1}}-\boldsymbol{t}_{\mathbf{2}}\right]$ : When $S_{1} S_{2} S_{3}=100, Q_{1}$ is reversely turned on, $Q_{2}$ and $Q_{3}$ are turned off. The current flow paths are shown in Fig.4 (b). During this state, $U_{\text {high }}$ charges $C_{\text {high }}$, while $C_{2}$ is connected in series with $L_{2}$ to charge $C_{1}$ through $Q_{1} . L_{1}$ also supplies energy for the load $R_{\text {load Buck }}$ through $Q_{1}$. By means of Fig.4 (b), the following equations can be obtained in state 1 :

$$
\begin{gathered}
\left\{\begin{array}{l}
U_{L 1}=U_{C 2}-U_{C 1} \\
U_{L 2}=-U_{\text {low }} \\
U_{\text {high }}=U_{C 3}
\end{array}\right. \\
\left\{\begin{array}{l}
i_{C 1 \_\left(1-d_{\text {Buck }}\right)}=i_{L 2} \\
i_{C 2 \_\left(1-d_{\text {Buck }}\right)}=-i_{L 2} \\
i_{C 3 \_\left(1-d_{\text {Buck }}\right)}=I_{\text {high }} \\
\left.i_{L 1}=I_{\text {low }}+i_{\text {Clow_(1-d duck }}\right)
\end{array}\right.
\end{gathered}
$$

By applying the volt-second balance principle on $L_{1}$ and $L_{2}$ with (8) and (10), the relationship between the voltage gain $M_{\text {Buck }}$ and the duty cycle $d_{\text {Buck }}$ in CCM can be obtained as

$$
M_{\text {Buck }}=\frac{d_{\text {Buck }}}{2-d_{\text {Buck }}}
$$

and the voltage stresses across the capacitors $C_{1}$ and $C_{2}$ can be described as 


$$
\left\{\begin{array}{l}
U_{C 1}=\frac{U_{\text {low }}}{d_{\text {Buck }}}=\frac{U_{\text {high }}}{2-d_{\text {Buck }}} \\
U_{C 2}=\frac{\left(1-d_{\text {Buck }}\right) U_{\text {low }}}{d_{\text {Buck }}}=\frac{\left(1-d_{\text {Buck }}\right) U_{\text {high }}}{2-d_{\text {Buck }}}
\end{array}\right.
$$

By applying the ampere-second balance principle on capacitors with (9) and (11), the average inductor currents $I_{L 1}$ and $I_{L 2}$ in the step-down mode can be written as

$$
\left\{\begin{array}{l}
I_{L 1}=I_{\text {low }} \\
I_{L 2}=\frac{d_{\text {Buck }}}{2-d_{\text {Buck }}} I_{\text {low }}
\end{array}\right.
$$

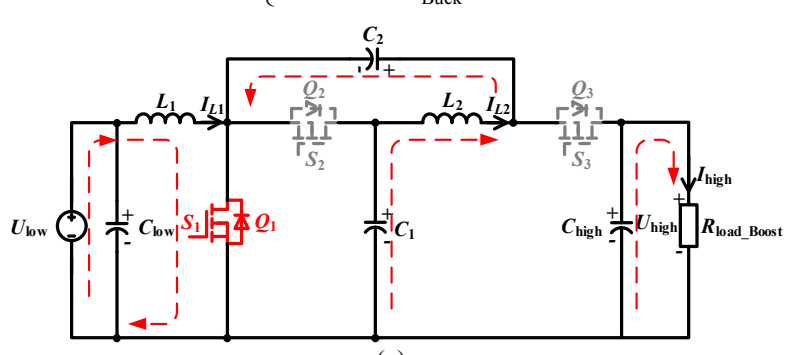

(a)

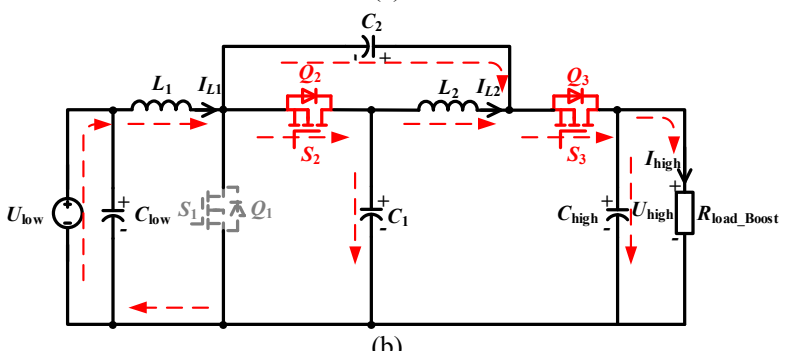

(b)

Fig.3 Current-flow paths of the proposed converter in the step-up mode. (a) State 0: $S_{1} S_{2} S_{3}=100$. (b) State 1: $S_{1} S_{2} S_{3}=011$.

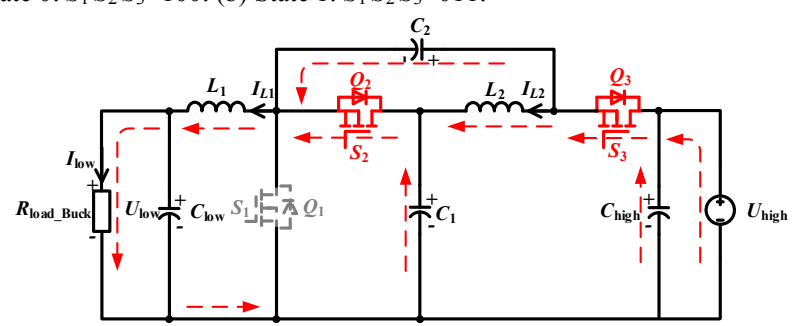

(a)

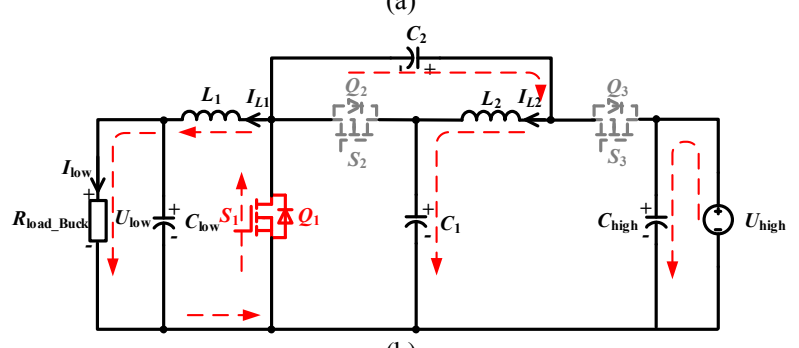

(b)

Fig.4 Current-flow paths of the proposed converter in the step-down mode. (a) State 0: $S_{1} S_{2} S_{3}=011$. (b) State 1: $S_{1} S_{2} S_{3}=100$.

\section{Bidirectional Operating Control Strategy of the Proposed Converter}

The bidirectional power flow control strategy of the proposed switched-quasi-Z-source converter is shown in Fig.5. The proposed converter is interfaced between the high voltage DC bus and the low voltage super capacitor bank.
The two operating modes of the converter in the hybrid energy sources system can be switched by judging the positive or negative polar of the control signal $I_{\text {sgn }}$, which should be provided by the energy management system omitted in this paper.

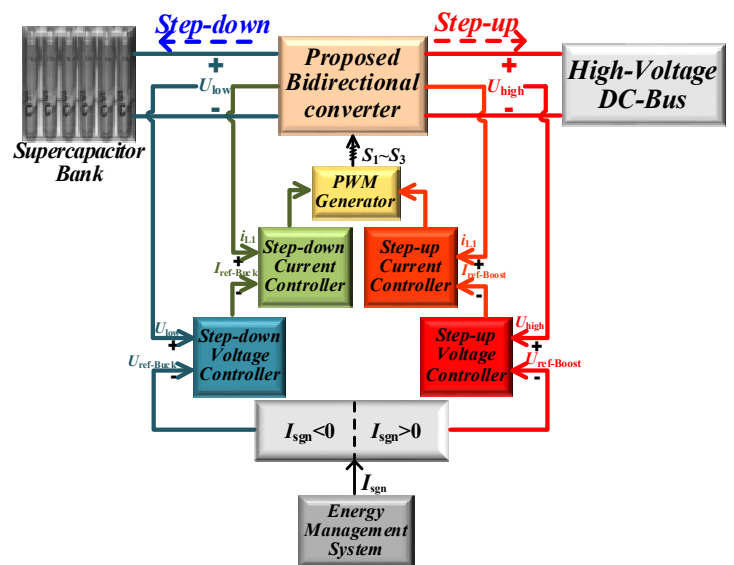

Fig. 5 Bidirectional power flow control strategy of the proposed converter.

1). When $I_{\text {sgn }}>0$, the controller enables the converter to operate in the step-up mode. At this point, the step-up mode reference voltage $U_{\text {ref-Boost }}$ is output by the step-up mode voltage controller with consideration of the feedback voltage $U_{\text {high }}$ from the high voltage DC bus. In addition, the reference current $I_{\text {ref Boost }}$ generated by the voltage controller with consideration of the feedback current $i_{L 1}$ from the inductor $L_{1}$ are used to produce the control variable by the step-up mode current controller. As a result, the corresponding three gate signals $S_{1} \sim S_{3}$ are generated by the PWM generator in the step-up mode.

2 ). When $I_{\mathrm{sgn}}<0$, the controller switches the converter to operate in the step-down mode. Similarly, the step-down mode reference voltage $U_{\text {ref-Buck }}$ is given in the step-down mode voltage controller with the feedback voltage $U_{\text {low }}$ from the super capacitor bank. In addition, the reference current $I_{\text {ref Buck }}$ generated by the voltage controller and the feedback current $i_{L 1}$ from the inductor $L_{1}$ are also used to produce the control variable by the step-down mode current controller. Therefore, the corresponding three gate signals $S_{1} \sim S_{3}$ are generated by the PWM generator in the step-down mode.

\section{PARAMETERS DESIGN AND ANALYSIS}

\section{A. Parameters Design of the Power Switches}

\section{Voltage Stress on the Power Switches}

The voltage drop of the power switch is ignored. According to the circuit of the step-up mode, as shown in Fig.3 (a) and (b) (or the circuit of the step-down mode, as shown in Fig.4 (a) and (b)), and the Kirchhoff's voltage law (KVL), the voltage stress on $Q_{1}-Q_{3}$ in the step-up and the step-down modes can be obtained as

$$
\begin{gathered}
U_{Q 1 \_ \text {Boost }}=U_{Q 2 \_ \text {Boost }}=U_{Q 3 \_ \text {Boost }}=\frac{U_{\text {low }}}{1-d_{\text {Boost }}}=\frac{U_{\text {high }}}{1+d_{\text {Boost }}} \\
U_{Q 1 \_ \text {Buck }}=U_{Q 2 \_ \text {Buck }}=U_{Q 3 \_ \text {Buck }}=\frac{U_{\text {low }}}{d_{\text {Buck }}}=\frac{U_{\text {high }}}{2-d_{\text {Buck }}}
\end{gathered}
$$

where $d_{\text {Boost }}=1-d_{\text {Buck. }}$. Therefore, the voltage stress on $Q_{1}-Q_{3}$ is the same both in the step-up and step-down modes, according to (15) and (16). 


\section{Current Stress on the Power Switches}

Similarly, according to the circuit of the step-up mode, as shown in Fig.3 (a) and (b) (or the circuit of the step-down mode, as shown in Fig.4 (a) and (b)), and the Kirchhoff's current law (KCL), the current stress on $Q_{1}-Q_{3}$ in the step-up and the step-down modes can be obtained as

$$
\begin{aligned}
& \left\{\begin{array}{l}
I_{Q 1 \_ \text {Boost }}=\frac{2}{1-d_{\text {Boost }}} I_{\text {high }} \\
I_{Q 2 \_ \text {Boost }}=I_{Q 3 \_ \text {Boost }}=-\frac{1}{1-d_{\text {Boost }}} I_{\text {high }}
\end{array}\right. \\
& \left\{\begin{array}{l}
I_{Q_{1} \text { Buck }}=-\frac{2}{2-d_{\text {Buck }}} I_{\text {low }} \\
I_{Q 2 \_ \text {Buck }}=I_{Q 3 \_ \text {Buck }}=\frac{1}{2-d_{\text {Buck }}} I_{\text {low }}
\end{array}\right.
\end{aligned}
$$

where $d_{\text {Boost }}=1-d_{\text {Buck }}$. As a result, the current stress on $Q_{1}$ is twice as big as that of $Q_{2}$ and $Q_{3}$ both in the step-up and the step-down modes, in terms of (17) and (18).

\section{B. Comparisons with Other Converters}

Under the premise of the same duty cycle and without considering the power loss, the proposed topology is compared with the traditional two-level bidirectional DC-DC converter, the bidirectional Buck-Boost converter in [31], the traditional three-level bidirectional DC-DC converter in [10], the quadratic DC-DC converter in [32], the classical Z-source converter in [29], the novel Z-source DC-DC converter in [30], the classical quasi-Z-source bidirectional DC-DC converter in [21] and the bidirectional DC-DC converter with a switched-capacitor cell in [27], as shown in TABLE I and TABLE II. The voltage gain against the duty cycle curves of these seven converters in two modes are plotted in Fig.6. According to TABLE I, TABLE II and Fig.6, when the duty cycle of the proposed converter varies between 0.2 and 0.8 , the voltage gain in the step-up mode is between 1.5 and 9 , and voltage gain in the step-down mode is between $1 / 9$ and $2 / 3$.

Compared with the traditional two-level bidirectional DCDC converter and Buck-Boost converter in [31], the proposed converter needs an additional power switch, and the current stress on the power switches is relatively large. However, it not only greatly reduces the voltage stress across the power switches, but also expands the voltage gain range. Although the switch voltage and current stresses of the proposed converter are slightly higher than those of the traditional three-level bidirectional converter in [10], the former requires less number of power switches. Moreover, the voltage gain range is improved more. Compared with the quadratic converter in [32], the proposed one requires an extra capacitor, but reduces one power switch. In addition, the voltage and current stresses on the power switches of the proposed converter are reduced significantly. Although the former has a higher voltage gain, its cascaded structure determines its efficiency is lower than the proposed converter. Compared with the classical Z-source and quasi-Z-source DC-DC converters in [21] and [29], the proposed converter needs the same number of components as those converters. However, the proposed converter remarkably reduces the voltage and current stresses on the power switches, at the cost of reducing the voltage gain a bit, and it has a common ground. Compared with the novel Z-source DC-DC converter in [30], the proposed one requires an extra power switch, but reduces one inductor. In addition, the voltage and current stresses on the power switches of the proposed converter are reduced significantly, and it still has the advantage of a common ground. Compared with the bidirectional DC-DC converter with a switched- capacitor cell in [27], the advantage of the proposed converter lies in an absolute common ground structure, although they have the same number of components, the same reduced voltage and current stresses, and the same voltage gain.

TABLE I COMPARISON ON NUMBER OF COMPONENTS

\begin{tabular}{cccc}
\hline \hline Topology & Power switch & Capacitor & Inductor \\
\hline $\begin{array}{c}\text { Proposed converter } \\
\text { Two-level converter }\end{array}$ & 3 & 4 & 2 \\
$\begin{array}{c}\text { Buck-Boost converter } \\
\text { in [31] }\end{array}$ & 2 & 2 & 1 \\
$\begin{array}{c}\text { Three-level converter } \\
\text { in [10] }\end{array}$ & 2 & 2 & 1 \\
$\begin{array}{c}\text { Quadratic converter in } \\
\text { [32] }\end{array}$ & 4 & 3 & 1 \\
$\begin{array}{c}\text { Classical Z-source } \\
\text { converter in [29] } \\
\text { Novel Z-source } \\
\text { converter in [30] } \\
\begin{array}{c}\text { Classical } \\
\text { Quasi-Z-source } \\
\text { converter in [21] }\end{array}\end{array}$ & 3 & 3 & 2 \\
$\begin{array}{c}\text { Switched-capacitor } \\
\text { converter in [27] }\end{array}$ & 3 & 4 & 2 \\
\hline \hline
\end{tabular}

\begin{tabular}{|c|c|c|c|c|c|}
\hline \multirow[t]{2}{*}{ Mode } & \multirow[t]{2}{*}{ Topology } & \multirow[t]{2}{*}{ Voltage gain } & \multirow[t]{2}{*}{ Voltage stress } & \multicolumn{2}{|l|}{ Current stress } \\
\hline & & & & $Q_{2}$ & $Q_{3}\left(\& Q_{4}\right)$ \\
\hline \multirow{8}{*}{$\begin{array}{l}\text { Step-up } \\
\text { mode }\end{array}$} & Proposed converter & $\left(1+d_{\text {Boost }}\right) /\left(1-d_{\text {Boost }}\right)$ & $U_{\text {high }} /\left(1+d_{\text {Boost }}\right)$ & $2 I_{\text {high }} /\left(1-d_{\text {Boost }}\right)$ & oost) \\
\hline & Two-level converter & $1 /\left(1-d_{\text {Boost }}\right)$ & $U_{\text {high }}$ & $I_{\text {high }} /\left(1-d_{\text {Boost }}\right)$ & / \\
\hline & $\begin{array}{c}\text { Buck-Boost } \\
\text { converter in [31] }\end{array}$ & $d_{\text {Boost }} /\left(1-d_{\text {Boost }}\right)$ & $U_{\text {high }} / d_{\text {Boost }}$ & $I_{\text {high }} d_{\text {Boost }} /\left(1-d_{\text {Boost }}\right)$ & / \\
\hline & $\begin{array}{l}\text { Three-level converter } \\
\text { in }[10]\end{array}$ & $1 /\left(1-d_{\text {Boost }}\right)$ & $U_{\text {high }} / 2$ & \multicolumn{2}{|l|}{$I_{\text {high }} /\left(1-d_{\text {Boost }}\right)$} \\
\hline & $\begin{array}{l}\text { Quadratic converter } \\
\text { in [32] }\end{array}$ & $1 /\left(1-d_{\text {Boost }}\right)^{2}$ & $U_{\text {high }} \&\left(1-d_{\text {Boost }}\right) U_{\text {high }}$ & $I_{\text {high }} /\left(1-d_{\text {Boost }}\right)^{2}$ & $I_{\text {high }} /\left(1-d_{\text {Boost }}\right)$ \\
\hline & $\begin{array}{l}\text { Classical Z-source } \\
\text { converter in [29] }\end{array}$ & $1 /\left(1-2 d_{\text {Boost }}\right)$ & $U_{\text {high }}$ & $2 I_{\text {high }} /\left(1-2 d_{\text {Boost }}\right)$ & $I_{\text {high }} /\left(1-d_{\text {Boost }}\right)$ \\
\hline & $\begin{array}{l}\text { Novel } Z \text {-source } \\
\text { converter in [30] }\end{array}$ & $\left(1-d_{\text {Boost }}\right) /\left(1-2 d_{\text {Boost }}\right)$ & $U_{\text {high }} /\left(1-d_{\text {Boost }}\right)$ & $I_{\text {high }}\left(1-d_{\text {Boost }}\right) /\left(1-2 d_{\text {Boost }}\right)$ & / \\
\hline & $\begin{array}{c}\text { Classical } \\
\text { Quasi-Z-source }\end{array}$ & $1 /\left(1-2 d_{\text {Boost }}\right)$ & $U_{\text {high }}$ & $\begin{array}{cc}\left.1-2 d_{\text {Boost }}\right) & I_{\text {high }} /\left(\left(1-2 d_{\text {Boost }}\right)\right. \\
\left.\left(1-d_{\text {Boost }}\right)\right)\end{array}$ & $I_{\text {high }} /\left(1-d_{\text {Boost }}\right)$ \\
\hline
\end{tabular}

TABLE II COMPARISON OF VOLTAGE GAIN AND VOLTAGE AND CURRENT STRESSES 


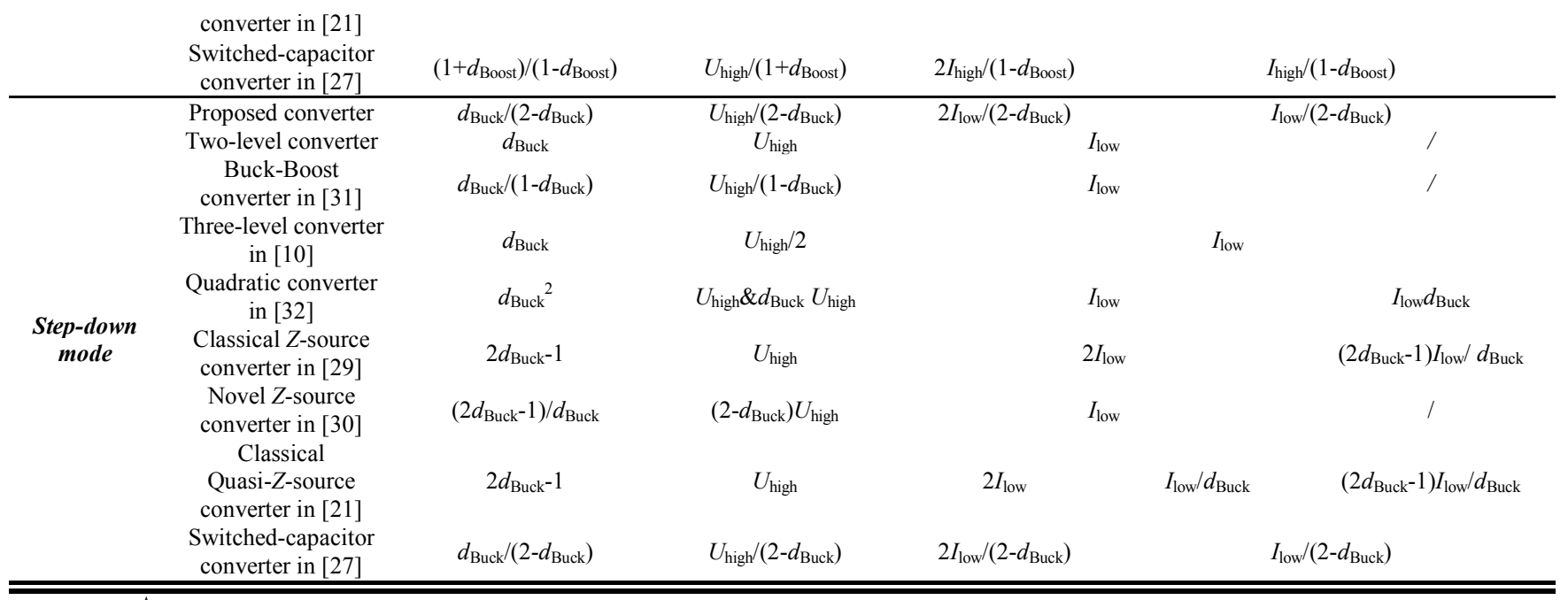

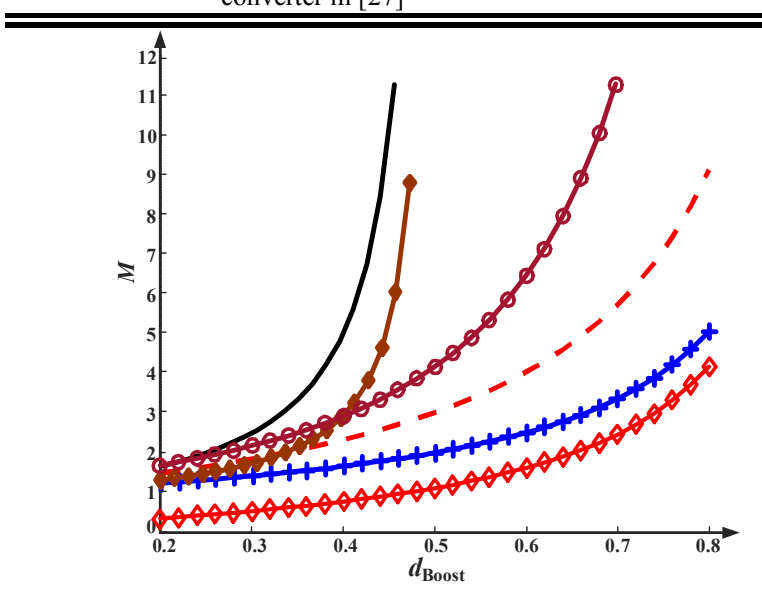

(a)

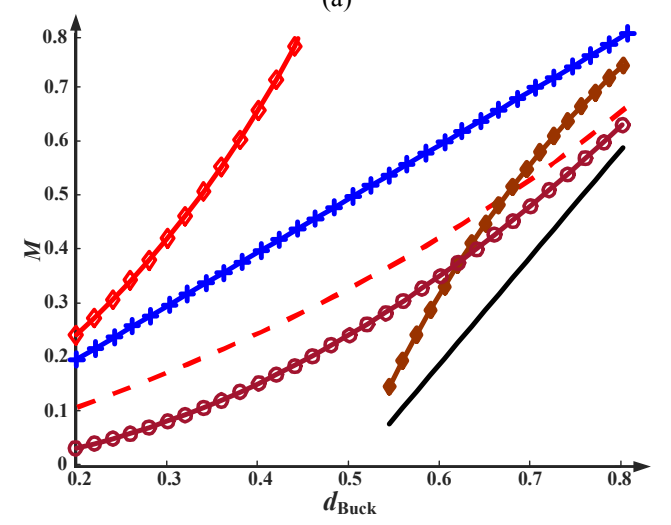

(b)

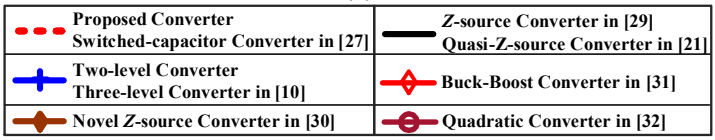

Fig.6 Comparisons of voltage gain against duty cycle. (a) Step-up mode. (b) Step-down mode.

\section{Small Signal Analysis and Voltage Loop Controller Design}

It is assumed that the inductor currents $i_{L 1}(t)$, and $i_{L 2}(t)$, capacitor voltages $u_{C 1}(t), u_{C 2}(t), u_{\text {Clow }}(t)$ and $u_{\text {Chigh }}(t)$ are the state variables. As shown in Fig.3 (b) and Fig.4 (a), the capacitor voltages $u_{C 1}(t), u_{C 2}(t)$ and $u_{C h i g h}(t)$ are mutually coupled, and there is an invalid state variable. By introducing the series resistance $r$ of the capacitor $C_{\text {high }}$, the coupling between the capacitors $C_{1}, C_{2}$ and $C_{\text {high }}$ can be removed to avoid an invalid state variable.

When the inductor current ripple and the capacitor voltage ripple are neglected, the state space averaging method can be adopted to derive the small signal $\mathrm{AC}$ equation of the proposed converter in the step-up mode:

$\left[\begin{array}{l}\frac{\mathrm{d} \hat{i}_{L 1}(t)}{\mathrm{d} t} \\ \frac{\mathrm{d} \hat{i}_{L 2}(t)}{\mathrm{d} t} \\ \frac{\mathrm{d} \hat{u}_{C 1}(t)}{\mathrm{d} t} \\ \frac{\mathrm{d} \hat{u}_{C 2}(t)}{\mathrm{d} t} \\ \frac{\mathrm{d} \hat{u}_{\text {Chigh }}(t)}{\mathrm{d} t}\end{array}\right]=\left[\begin{array}{ccccc}0 & 0 & -\frac{1-D}{L_{1}} & 0 & 0 \\ 0 & -\frac{r D}{L_{2}} & \frac{1}{L_{2}} & -\frac{D}{L_{2}} & -\frac{1-D}{L_{2}} \\ \frac{1-D}{C_{1}} & -\frac{1}{C_{1}} & -\frac{1-D}{C_{1} r} & -\frac{1-D}{C_{1} r} & \frac{1-D}{C_{1} r} \\ 0 & \frac{D}{C_{2}} & -\frac{1-D}{C_{2} r} & -\frac{1-D}{C_{2} r} & \frac{1-D}{C_{2} r} \\ 0 & \frac{1-D}{C_{\text {high }}} & \frac{1-D}{C_{\text {high }} r} & \frac{1-D}{C_{\text {high }} r} & -\frac{1}{C_{\text {high }} R}-\frac{1-D}{C_{\text {high }} r}\end{array}\right]\left[\begin{array}{l}\hat{i}_{L 1}(t) \\ \hat{i}_{L 2}(t) \\ \hat{u}_{C 1}(t) \\ \hat{u}_{C 2}(t) \\ \hat{u}_{C \text { high }}(t)\end{array}\right]$

$$
\begin{aligned}
& +\left[\begin{array}{c}
\frac{1}{L_{1}} \\
0 \\
0 \\
0 \\
0
\end{array}\right] \hat{u}_{\text {in }}(t)+\left[\begin{array}{ccccc}
0 & 0 & \frac{1}{L_{1}} & 0 & 0 \\
0 & -\frac{r}{L_{2}} & 0 & -\frac{1}{L_{2}} & \frac{1}{L_{2}} \\
-\frac{1}{C_{1}} & 0 & \frac{1}{C_{1} r} & \frac{1}{C_{1} r} & -\frac{1}{C_{1} r} \\
0 & \frac{1}{C_{2}} & \frac{1}{C_{2} r} & \frac{1}{C_{2} r} & -\frac{1}{C_{2} r} \\
0 & -\frac{1}{C_{\text {high }}} & -\frac{1}{C_{\text {high }} r} & -\frac{1}{C_{\text {high }} r} & \frac{1}{C_{\text {high }} r}
\end{array}\right]\left[\begin{array}{l}
I_{L 1} \\
I_{L 2} \\
U_{C 1} \\
U_{C 2} \\
U_{\text {Chigh }}
\end{array}\right] \hat{d}(t) \\
& \hat{u}_{\text {high }}(t)=\left[\begin{array}{lllll}
0 & 0 & 0 & 0 & 1
\end{array}\right]\left[\begin{array}{lllll}
\hat{L}_{L 1}(t) & \hat{i}_{L 2}(t) & \hat{u}_{C 1}(t) & \hat{u}_{C 2}(t) & \hat{u}_{\text {Chigh }}(t)
\end{array}\right]^{\mathrm{T}}
\end{aligned}
$$

By substituting the corresponding component parameters shown in TABLE III into (19), the control to output voltage transfer function of the proposed converter in the step-up mode can be obtained as follows:

$$
G_{u_{\text {high }} d_{\text {Boost }}}(s)=\frac{\hat{u}_{\text {high }}(s)}{\hat{d}_{\text {Boost }}(s)}
$$

$=\frac{-2.7 \times 10^{3} \cdot s^{4}-8.8 \times 10^{8} \cdot s^{3}+1.9 \times 10^{13} \cdot s^{2}-5.2 \times 10^{15} \cdot s+7.5 \times 10^{19}}{s^{5}+1.7 \times 10^{5} \cdot s^{4}+8.8 \times 10^{6} \cdot s^{3}+8.6 \times 10^{11} \cdot s^{2}+7.3 \times 10^{12} \cdot s+7.7 \times 10^{16}}$

Similarly, the small signal AC equation of the converter in the step-down mode can be derived: 
$\left[\begin{array}{l}\frac{\mathrm{d} \hat{i}_{L 1}(t)}{\mathrm{d} t} \\ \frac{\mathrm{d} \hat{i}_{L 2}(t)}{\mathrm{d} t} \\ \frac{\mathrm{d} \hat{u}_{C 1}(t)}{\mathrm{d} t} \\ \frac{\mathrm{d} \hat{u}_{C 2}(t)}{\mathrm{d} t} \\ \frac{\mathrm{d} \hat{u}_{C \text { low }}(t)}{\mathrm{d} t}\end{array}\right]=\left[\begin{array}{ccccc}0 & 0 & \frac{D}{L_{1}} & 0 & -\frac{1}{L_{1}} \\ 0 & -\frac{r(1-D)}{L_{2}} & -\frac{1}{L_{2}} & \frac{1-D}{L_{2}} & 0 \\ -\frac{D}{C_{1}} & \frac{1}{C_{1}} & -\frac{D}{C_{1} r} & -\frac{D}{C_{1} r} & 0 \\ 0 & -\frac{1-D}{C_{2}} & -\frac{D}{C_{2} r} & -\frac{D}{C_{2} r} & 0 \\ \frac{1}{C_{\text {low }}} & 0 & 0 & 0 & -\frac{1}{C_{\text {low }} R}\end{array}\right]\left[\begin{array}{l}\hat{i}_{L 1}(t) \\ \hat{i}_{L 2}(t) \\ \hat{u}_{C 1}(t) \\ \hat{u}_{C 2}(t) \\ \hat{u}_{C l o w}(t)\end{array}\right]$

$+\left[\begin{array}{c}0 \\ \frac{D}{L_{2}} \\ \frac{D}{C_{1} r} \\ \frac{D}{C_{2} r} \\ 0\end{array}\right] \hat{u}_{\text {high }}(t)+\left[\begin{array}{ccccc}0 & 0 & \frac{1}{L_{1}} & 0 & 0 \\ 0 & \frac{r}{L_{2}} & 0 & -\frac{1}{L_{2}} & 0 \\ -\frac{1}{C_{1}} & 0 & -\frac{1}{C_{1} r} & -\frac{1}{C_{1} r} & 0 \\ 0 & \frac{1}{C_{2}} & -\frac{1}{C_{2} r} & -\frac{1}{C_{2} r} & 0 \\ 0 & 0 & 0 & 0 & 0\end{array}\right]\left[\begin{array}{l}I_{L 1} \\ I_{L 2} \\ U_{C 1} \\ U_{C 2} \\ U_{C \text { low }}\end{array}\right] \hat{d}(t)+\left[\begin{array}{c}0 \\ \frac{\hat{d}(t)}{L_{2}} \\ \frac{\hat{d}(t)}{C_{1} r} \\ \hat{d}(t) \\ \frac{C_{2} r}{0}\end{array}\right] U_{\text {high }}$

$\hat{u}_{\text {low }}(t)=\left[\begin{array}{lllll}0 & 0 & 0 & 0 & 1\end{array}\right]\left[\begin{array}{lllll}\hat{i}_{L 1}(t) & \hat{i}_{L 2}(t) & \hat{u}_{C 1}(t) & \hat{u}_{C 2}(t) & \hat{u}_{\text {Clow }}(t)\end{array}\right]^{\top}$

By substituting the corresponding component parameters shown in TABLE III into (21), the control to output voltage transfer function of the proposed converter in the step-down mode can also be obtained as follows:

$$
\begin{aligned}
& G_{u_{\text {low }} d_{\text {Buck }}}(s)=\frac{\hat{u}_{\text {low }}(s)}{\hat{d}_{\text {Buck }}(s)} \\
& =\frac{1.3 \times 10^{-10} s^{3}-4.0 \times 10^{-6} s^{2}+2.0 s \times 10^{-3}-43.74}{9.4 \times 10^{-20} s^{5}+2.6 \times 10^{-14} s^{4}-4.0 \times 10^{-9} s^{3}-1.6 \times 10^{-7} s^{2}-4.7 \times 10^{-2} s-1}
\end{aligned}
$$

The proposed converter adopts an output voltage loop, and the voltage loop control scheme can be obtained as shown in Fig.7, where $G_{\text {uod }}(s)$ is the control to output voltage transfer function of the proposed converter, $G_{\mathrm{m}}(s)$ is the transfer function of pulse-width modulator, $H(s)$ is the feedback transfer function and $G_{\mathrm{c}}(s)$ is the voltage controller transfer function. In the closed-loop system of the proposed converter, the transfer functions $G_{\mathrm{m}}(s)=1, H(s)=1$ are unitized, and the transfer function $G_{\mathrm{c}}(s)$ of the PI (Proportional-Integral) voltage controller is shown in (23). Therefore, by adjusting the PI parameters $K_{\mathrm{p}}$ and $K_{\mathrm{i}}$ of the voltage loop controller, the closed-loop system of the proposed converter can achieve a better stability performance.

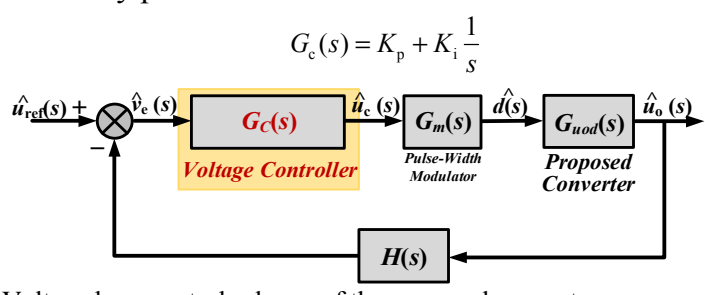

Fig.7 Voltage loop control scheme of the proposed converter.

As to the output voltage closed-loop system of the proposed converter, when the converter operates in the step-up mode, the PI voltage controller parameters are $K_{\mathrm{p}}=0.001$, and $K_{\mathrm{i}}=0.0001$. Therefore, the corresponding open-loop transfer function $G_{0 \text { Boost }}(s)$ can be obtained as follows:

$G_{0 \_ \text {Boost }}(s)=G_{\mathrm{c}}(s) G_{\mathrm{m}}(s) G_{u_{\text {higho }} d_{\text {Boost }}}(s) H(s)$

$=\frac{-2.7 \cdot s^{5}-8.8 \times 10^{5} \cdot s^{4}+1.9 \times 10^{10} \cdot s^{3}-5.2 \times 10^{12} \cdot s^{2}+7.5 \times 10^{16} \cdot s+7.5 \times 10^{15}}{s^{6}+1.7 \times 10^{5} \cdot s^{5}+8.8 \times 10^{6} \cdot s^{4}+8.6 \times 10^{1} \cdot s^{3}+7.3 \times 10^{2} \cdot s^{2}+7.7 \times 10^{6} \cdot s}$ $s^{6}+1.7 \times 10^{5} \cdot s^{5}+8.8 \times 10^{6} \cdot s^{4}+8.6 \times 10^{11} \cdot s^{3}+7.3 \times 10^{12} \cdot s^{2}+7.7 \times 10^{16} \cdot s$
Similarly, when the converter operates in the step-down mode, the PI voltage controller parameters are $K_{\mathrm{p}}=0.0015$, and $K_{\mathrm{i}}=0.01$. Thus, the corresponding open-loop transfer function $G_{0 \_ \text {Buck }}(s)$ can be obtained as follows:

$G_{0 \_ \text {Buck }}(s)=G_{\mathrm{c}}(s) G_{\mathrm{m}}(s) G_{u_{\text {loud }} d_{\text {Buck }}}(s) H(s)$

$=\frac{1.1 \times 10^{6} \cdot s^{4}+1.2 \times 10^{11} \cdot s^{3}+6.6 \times 10^{12} \cdot s^{2}+6.7 \times 10^{17} \cdot s+4.5 \times 10^{18}}{s^{6}+1.1 \times 10^{5} \cdot s^{5}+5.6 \times 10^{7} \cdot s^{4}+1.1 \times 10^{12} \cdot s^{3}+2.5 \times 10^{14} \cdot s^{2}+2.8 \times 10^{18} \cdot s}$

As a result, the Bode diagrams of the open-loop transfer functions with the PI voltage controllers in the step-up and step-down operating modes can be obtained as shown in Fig.8 (a) and Fig.8 (b), respectively, in terms of (24) and (25). It can be seen that when the proposed converter operates in the step-up and step-down modes, the amplitude margin $K_{\mathrm{g}}$ and the phase margin $\gamma$ are both greater than 0 . Therefore, the closed-loop system of the proposed converter, which adopts the PI voltage controller, can operate stably.

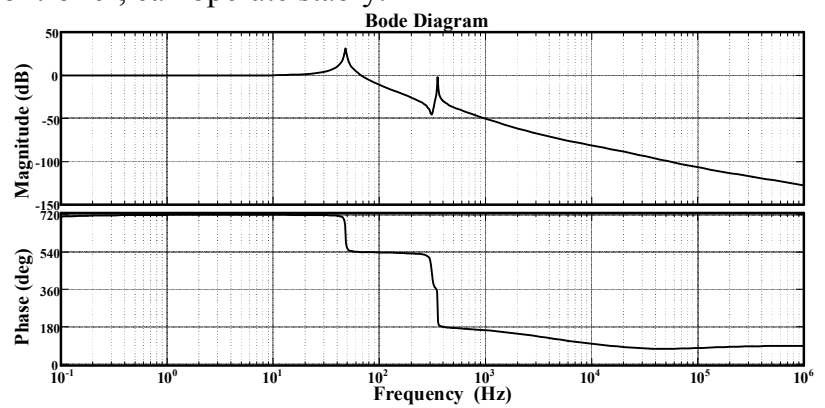

(a)

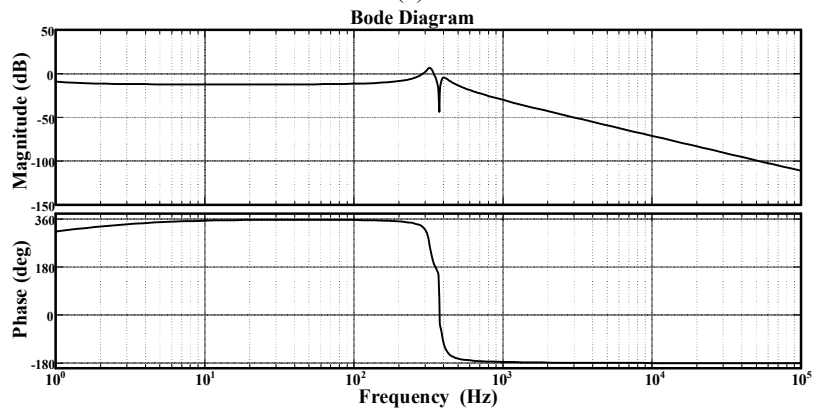

(b)

Fig. 8 Bode plots of the small-signal open-loop transfer functions with PI voltage controllers. (a) The step-up mode. (b) The step-down mode.

\section{EXPERIMENTAL RESULTS AND ANALYSIS}

In order to validate the effectiveness of the proposed converter, a $300 \mathrm{~W}$ prototype is developed, as shown in Fig.9. The specific parameters of the experimental prototype are given in TABLE III. A Texas Instruments microcontroller TMS32028335 is used for the voltage loop controller.

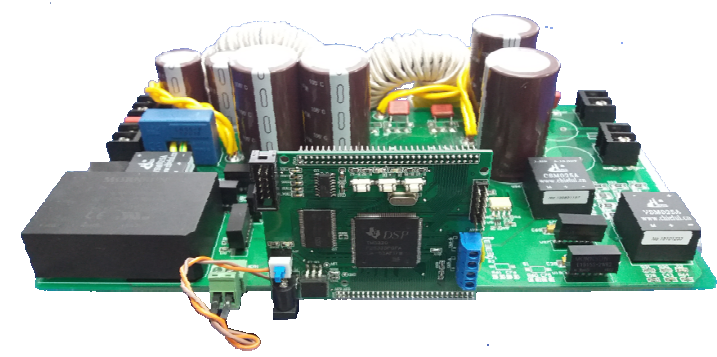

Fig.9 Prototype of the proposed converter. 


\section{TABLE III EXPERIMENTAL PARAMETERS OF THE CONVERTER}

\begin{tabular}{cc}
\hline \hline Parameter & Values \\
\hline Rated power: $P_{\mathrm{n}}$ & $300 \mathrm{~W}$ \\
Filtering capacitors: $C_{\text {low }} / C_{\text {high }}$ & $470 \mu \mathrm{F}$ \\
Switched capacitors: $C_{1} / C_{2}$ & $520 \mu \mathrm{F}$ \\
Inductor 1: $L_{1}$ & $434 \mu \mathrm{H}$ \\
Inductor $2: L_{2}$ & $600 \mu \mathrm{H}$ \\
High-side voltage: $U_{\text {high }}$ & $240 \mathrm{~V}$ \\
Low-side voltage: $U_{\text {low }}$ & $40 \sim 120 \mathrm{~V}$ \\
Switching frequency: $f_{\mathrm{s}}$ & $20 \mathrm{kHz}$ \\
Power MOSFETs: $Q_{1} \sim Q_{3}$ & IXTH $88 \mathrm{~N} 30 \mathrm{P}$ \\
\hline \hline
\end{tabular}

\section{A. Experimental Results in the Step-Up Mode}

When the proposed converter operates in the step-up mode at the rated condition, the gate signal and the voltage stress waveforms of $Q_{1}$, and the voltage stress waveforms of the synchronous rectifiers $Q_{2}$ and $Q_{3}$ are shown in Fig.10 and Fig.11, respectively. It can be seen that the voltage stress on $Q_{1}-Q_{3}$ is $140 \mathrm{~V}$ (slightly higher than half of the high-side voltage), which is consistent with the theoretical calculation.

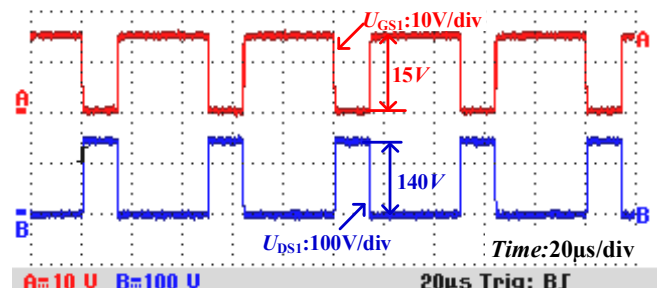

A= 10 U B 100 U

$$
\text { 20us Trig: BJ }
$$

Fig.10 Voltage stress across power switch $Q_{1}$ in the step-up mode.

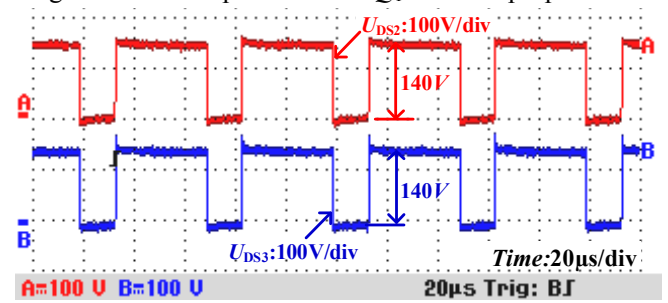

Fig. 11 Voltage stress across synchronous rectifiers $Q_{2}-Q_{3}$ in the step-up mode.

At the same condition, the current waveforms of $L_{1}$ and $L_{2}$ are shown in Fig.12. It can be seen that the current ripple rate of $L_{1}$ is about $28.57 \%$, and that of $L_{2}$ is about $200 \%$ due to its smaller average current value, which satisfy the design requirements of the inductors.

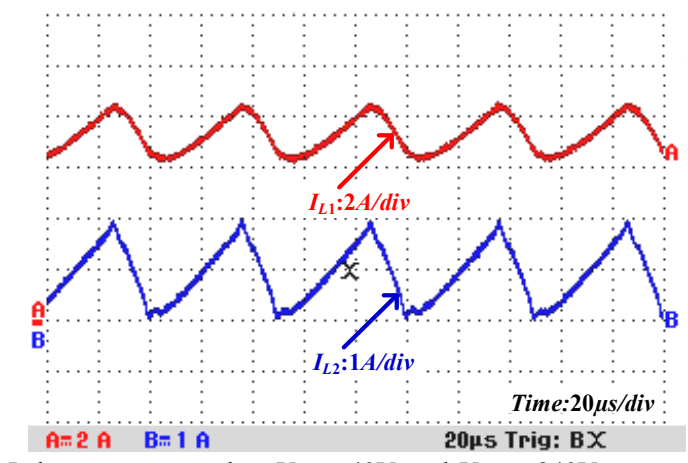

Fig. 12 Inductor currents, when $U_{\text {low }}=40 \mathrm{~V}$, and $U_{\text {high }}=240 \mathrm{~V}$.

Fig. 13 shows the dynamic behavior of the output voltage $U_{\text {high }}$ which keeps at $240 \mathrm{~V}$, when the input voltage $U_{\text {low }}$ changes from $120 \mathrm{~V}$ to $40 \mathrm{~V}$ over 11 seconds simulating the continuous discharging of the energy source and its terminal voltage drops.
It illustrates that the converter can achieve a wide voltage gain range from 2 to 6 .

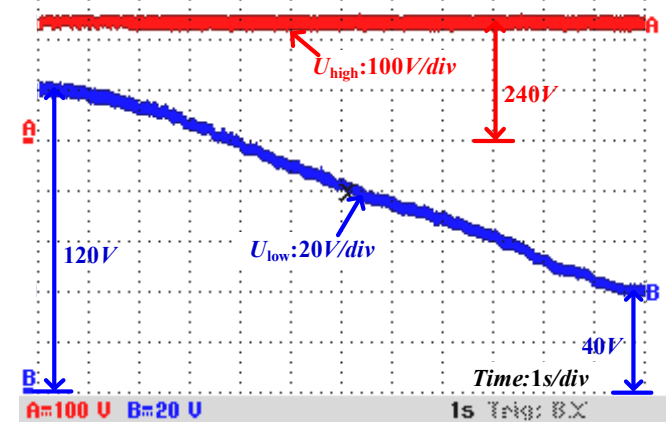

Fig.13 Input voltage $U_{\text {low }}$ and output voltage $U_{\text {high }}$ when input voltage changes from $120 \mathrm{~V}$ to $40 \mathrm{~V}$.

The output voltage and the load current are shown in Fig.14, when the output power $P_{\mathrm{o}}$ is step changed between $150 \mathrm{~W}$ and $300 \mathrm{~W}$. It can be seen that when the proposed converter operates under the voltage loop controller in the step-up mode, the output voltage $U_{\text {high }}$ can be nearly kept at $240 \mathrm{~V}$ and the transient voltage fluctuation is small enough to be neglected.

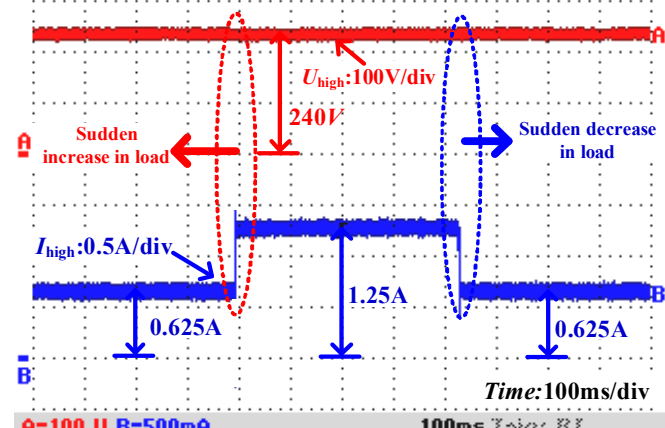

Fig.14 Output voltage and load current when output power $P_{\mathrm{o}}$ is step changed between $300 \mathrm{~W}$ and $150 \mathrm{~W}$ in step-up mode.

\section{B. Experimental Results in the Step-Down Mode}

When the proposed converter operates in the step-down mode at the rated condition, the gate signal and the voltage stress across $Q_{2}$, and the voltage stress across $Q_{3}$ and the synchronous rectifier $Q_{1}$ are shown in Fig.15 and Fig.16, respectively. It is clear that the voltage stress on $Q_{1}-Q_{3}$ is still $140 \mathrm{~V}$ (slightly higher than half of the high-side voltage), which also agrees with the theoretical calculation.

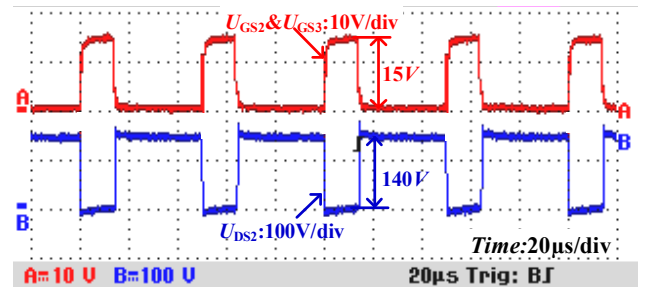

Fig. 15 Voltage stress across $Q_{2}$

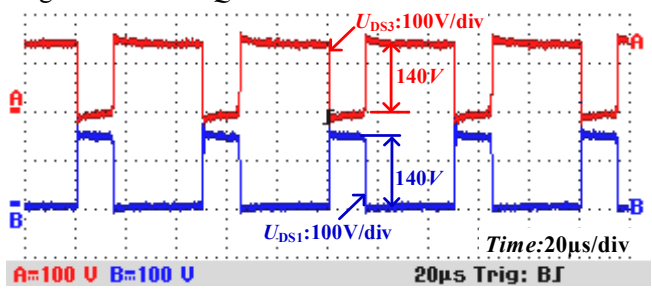

Fig.16 Voltage stress across $Q_{3}$ and synchronous rectifier $Q_{1}$. 
At the same condition, the currents of $L_{1}$ and $L_{2}$ are shown in Fig.17. It can be seen that the current ripple rate of $L_{1}$ is about $26.67 \%$ and that of $L_{2}$ is about $200 \%$ due to its smaller average current value, which also satisfy the design requirements of the inductors.

Fig. 18 shows the dynamic behavior of the output voltage $U_{\text {low }}$ when the input voltage $U_{\text {high }}$ maintains at $240 \mathrm{~V}$, and the output voltage $U_{\text {low }}$ is controlled to change from $40 \mathrm{~V}$ to $120 \mathrm{~V}$. This experimental result is used to simulate the continuous charging of the energy source, and its terminal voltage rises. When the input voltage $U_{\text {high }}$ keeps at $240 \mathrm{~V}$, the output voltage $U_{\text {low }}$ increases from $40 \mathrm{~V}$ to $120 \mathrm{~V}$ within 11 seconds, namely, the converter can obtain a wide voltage gain range from 0.16 to 0.5 in the step-down mode.

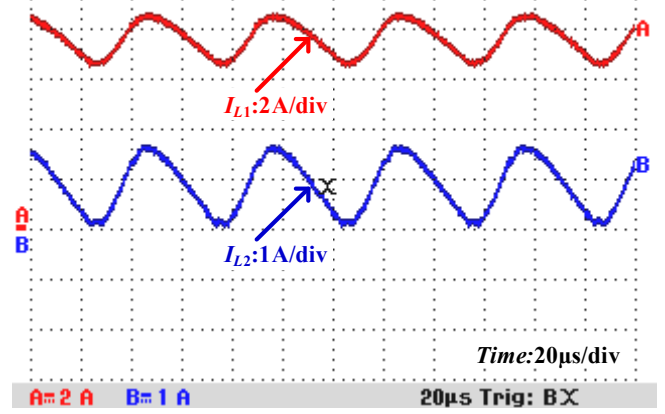

Fig. 17 Inductors current waveforms, when $U_{\text {high }}=240 \mathrm{~V}, U_{\text {low }}=40 \mathrm{~V}$.

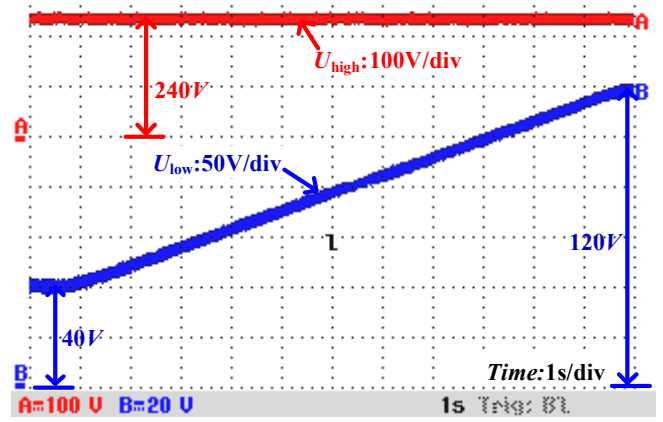

Fig.18 Input voltage $U_{\text {high }}$ and output voltage $U_{\text {low }}$ when output voltage changes from $40 \mathrm{~V}$ to $120 \mathrm{~V}$.

The output voltage and the load current are shown in Fig.19, when the output power $P_{\mathrm{o}}$ is step changed between $160 \mathrm{~W}$ and $320 \mathrm{~W}$ in the step-down mode. It can be seen that when the proposed converter operates under the output voltage closed loop control in the step-down mode, the output voltage $U_{\text {low }}$ can nearly be kept at $40 \mathrm{~V}$ and the voltage fluctuation is small enough to be neglected.

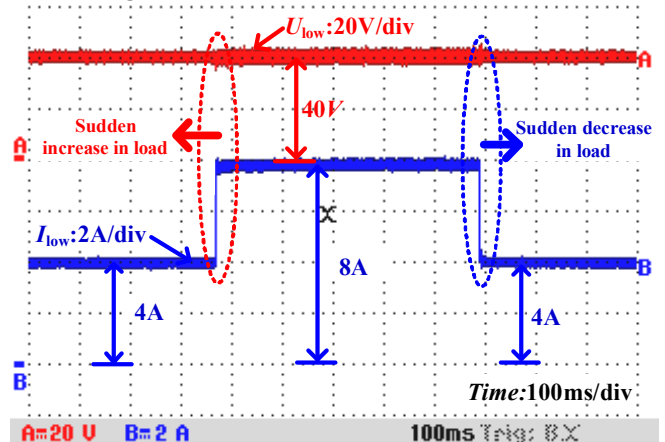

Fig. 19 Output voltage and load current when output power $P_{\mathrm{o}}$ is step changed between $320 \mathrm{~W}$ and $160 \mathrm{~W}$ in step-down mode.

\section{Experimental Results of Bidirectional Power Control of the Proposed Converter}

Fig. 20 shows the hybrid energy sources system for an electric vehicle, which is comprised of the super capacitor and the battery pack. The super capacitor bank is composed of four CSDWELL's super capacitor modules in series, and the battery pack is comprised of the lithium iron phosphate battery with a capacity of $20 \mathrm{Ah}$. In the hybrid energy sources system, the proposed switch-quasi-Z-source bidirectional DC-DC converter is interfaced between the high voltage DC bus and the low voltage super capacitor bank. The battery pack provides the average power for the DC bus through the bidirectional DC-DC converter, boosting the low voltage of the battery pack to match the high voltage of the DC bus.

When the vehicle is accelerating, the super capacitor bank supplies the instantaneous power required from the DC bus by the proposed DC-DC converter rapidly, due to the quick dynamic response characteristics of the super capacitor bank. During this process, the bidirectional DC-DC converter steps up the variable battery pack voltage to keep the constant high voltage of the $\mathrm{DC}$ bus with a voltage loop, and provides the average power for the DC bus. When the vehicle decelerates or brakes, the regenerative energy can be absorbed controllably by the super capacitor and the battery packs through the bidirectional DC-DC converters. When the vehicle operates at uniform speed, the battery pack provides the steady energy for the DC bus through the bidirectional DC-DC converter with the corresponding voltage-gain, and charges the super capacitor bank by the proposed converter if it is needed. According to the operating conditions previously described, the hybrid energy sources management system in electric vehicles provides the control signal $I_{\mathrm{sgn}}$ for the controller of the proposed converter. Then, the proposed converter can be controlled in the bidirectional power flow modes, according to the control strategy as shown in Fig.5.

The experimental results of the proposed converter in the bidirectional power control modes are shown in Fig.21. The currents $I_{\mathrm{sc}}$ and $I_{\text {bat }}$ represent the super capacitor current and battery current respectively. It is assumed that the current from the positive polar of the super capacitor bank/battery pack is in the positive polar direction.

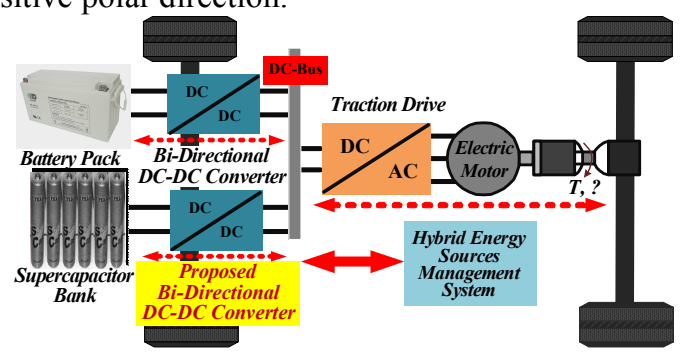

Fig.20 Hybrid energy sources system for an EV.

It can be seen that when the demand DC bus power is changed quickly from $400 \mathrm{~W}$ to $650 \mathrm{~W}$, which simulates the electric vehicle's accelerating process, the control signal $I_{\text {sgn }}$ that output from the hybrid energy sources management system is greater than 0. At the same time, the proposed converter responds quickly and operates in the step-up mode. The current $I_{\mathrm{sc}}$ increases quickly from $0 \mathrm{~A}$ to $5 \mathrm{~A}$ during approximately $20 \mathrm{~ms}$, and the super capacitor provides the instantaneous current $I_{\mathrm{sc}}$ for 
the DC bus, while the output current $I_{\text {bat }}$ of the battery increases very slowly. When $I_{\mathrm{sc}}$ falls to $0 \mathrm{~A}$ from $5 \mathrm{~A}, I_{\mathrm{bat}}$ rises gently from $8.8 \mathrm{~A}$ to $13 \mathrm{~A}$, and the battery provides the static power for the DC bus. Similarly, when the demand DC bus power is reduced quickly from $650 \mathrm{~W}$ to $400 \mathrm{~W}$, which simulates the electric vehicle's decelerating process, the control signal $I_{\text {sgn }}$ is less than 0 . At the same time, the proposed converter responds quickly and operates in the step-down mode. The current $I_{\mathrm{sc}}$ increases from zero to $-4 \mathrm{~A}$ over approximately $20 \mathrm{~ms}$, and the super capacitor absorbs the instantaneous power from the DC bus. When the current $I_{\mathrm{sc}}$ falls to $0 \mathrm{~A}$ from $-5 \mathrm{~A}$, the current $I_{\mathrm{bat}}$ is gradually reduced from $13 \mathrm{~A}$ to $8.8 \mathrm{~A}$, and the battery absorbs the power from the DC bus very slowly.

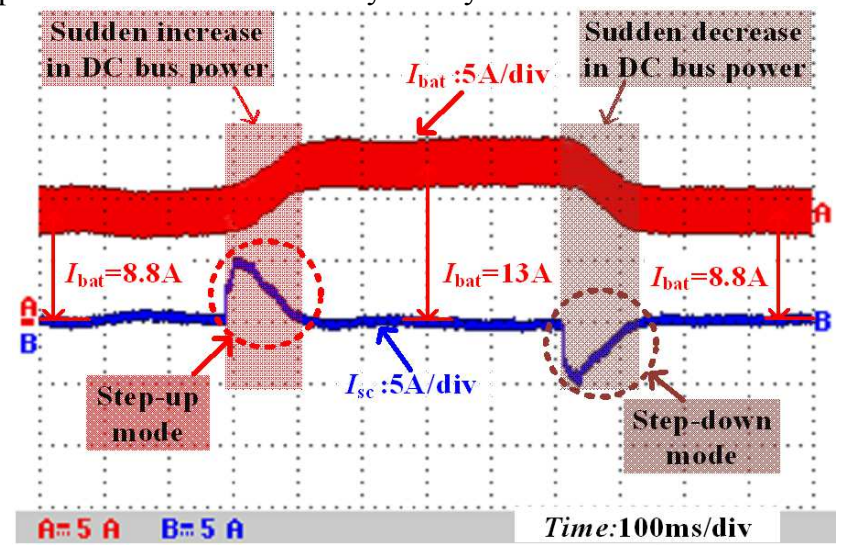

Fig.21 Experimental results of the proposed converter in the bidirectional power control modes.

Therefore, when electric vehicles have a sudden increase or decrease during the accelerating or decelerating process, the proposed converter can respond quickly according to the control signal $I_{\mathrm{sgn}}$. The super capacitor can provide or absorb the instantaneous power to ensure that the current of the battery changes more gently. As a result, the battery can be protected and the dynamic response of the whole powertrain system is improved.

\section{Efficiency Analysis of the Proposed Converter}

The experimental efficiencies at different voltage gains are shown in Fig.22. The experimental efficiency is measured by the power analyzer YOKOGAWA/WT3000.

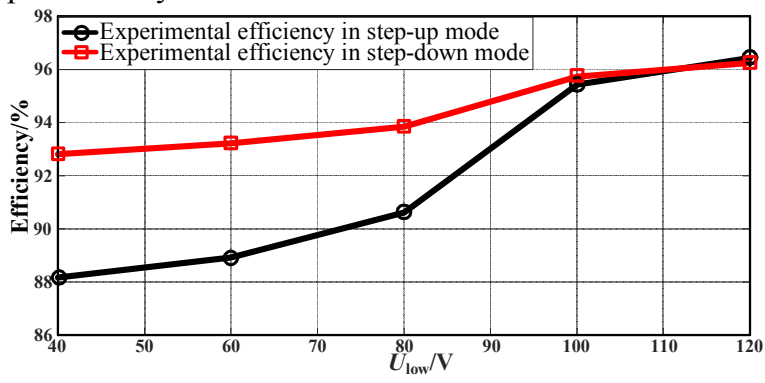

Fig.22 Efficiency of the proposed converter in the step-up and step-down modes with $U_{\text {high }}=240 \mathrm{~V}, U_{\text {low }}=40 \sim 120 \mathrm{~V}$ and $P_{\mathrm{o}}=300 \mathrm{~W}$.

From Fig.22, the maximum and minimum efficiencies of the proposed converter in the step-up mode are $96.44 \%$ and $88.17 \%$, respectively. And the maximum and minimum efficiencies of the proposed converter in the step-down mode are $96.24 \%$ and $92.31 \%$, respectively. It is noticed that the maximum measured efficiencies of the proposed converter in the step-up and step-down modes are very close to those of converters in [10], [16], [17] [25], [27] and [28]. As shown in Fig.22, with the increase of the low-side voltage, the efficiency of the proposed converter increases gradually for the same output power, due to the reduced losses caused by the decreasing input current.

\section{E. Power Loss Analysis of the Proposed Converter}

The calculated power loss distributions for the experiment when $U_{\text {low }}=120 \mathrm{~V}, U_{\text {high }}=240 \mathrm{~V}, P_{\mathrm{o}}=300 \mathrm{~W}$ and $d_{\text {Boost }}=1-d_{\text {Buck }}=$ 0.33 are shown in Fig. 23 .

When the proposed converter operates in step-up mode, the total losses of the converter are $10.68 \mathrm{~W}$, and the loss distribution is shown in Fig.23 (a). By analyzing the power losses distribution, it can be concluded that the major losses come from the switching losses of the power switches $Q_{1}-Q_{3}$ (i.e. $P_{2 \text { Boost }}=4.98 \mathrm{~W}$ ), which account for $46.63 \%$ of the total losses. The conduction losses of all power switches $Q_{1}-Q_{3}$ (i.e. $P_{Q_{\text {B Boost }}}=0.925 \mathrm{~W}$ ) account for $8.66 \%$ of the total losses. In addition to the power losses of the semiconductors, the copper losses $P_{\mathrm{Cu} \text { Boost }}$ of inductors $L_{1}$ and $L_{2}$ is $1.98 \mathrm{~W}$, which account for $19.75 \%$ of the total losses. And the core losses $P_{\mathrm{Fe} \text { Boost }}$ of inductors $L_{1}$ and $L_{2}$ account for $18.35 \%$ of the total losses, which is close to that of the copper losses. The capacitor losses $P_{\mathrm{C}_{-} \text {Boost }}$ of $C_{1}-C_{2}$ and $C_{\text {high }}$ is $0.7 \mathrm{~W}$, which account for $6.55 \%$ of the total losses.

Similarly, when the proposed converter operates in step-down mode, the total losses of the converter are $11.28 \mathrm{~W}$, and the loss distribution is shown in Fig.23 (b). By analyzing the power losses distribution, it can be concluded that the major losses also come from the switching losses of the power switches $Q_{1}-Q_{3}$ (i.e. $P_{2 \text { Buck }}=5.568 \mathrm{~W}$ ), which account for $49.36 \%$ of the total losses. The conduction losses of all power switches $Q_{1}-Q_{3}$ (i.e. $P_{Q \text { Buck }}=0.94 \mathrm{~W}$ ) account for $8.33 \%$ of the total losses. In addition to the power losses of the semiconductors, the copper losses $P_{\text {Cu_Buck }}$ of inductors $L_{1}$ and $L_{2}$ is $2.11 \mathrm{~W}$, which account for $18.71 \%$ of the total losses. And the core losses $P_{\mathrm{Fe} \text { Buck }}$ of inductors $L_{1}$ and $L_{2}$ account for $17.37 \%$ of the total losses, which is close to that of the copper losses. The capacitor losses $P_{\mathrm{C}_{-} \text {Buck }}$ of $C_{1}-C_{2}$ and $C_{\text {high }}$ is $0.702 \mathrm{~W}$, which account for $6.22 \%$ of the total losses.

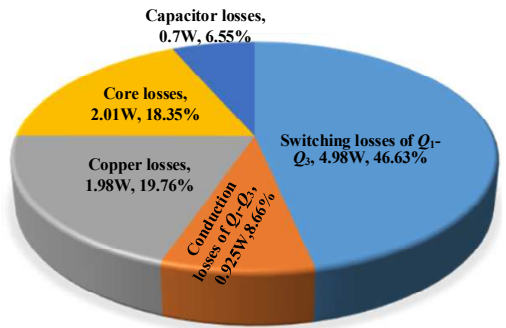

(a) Step-up mode Capacitor losses,

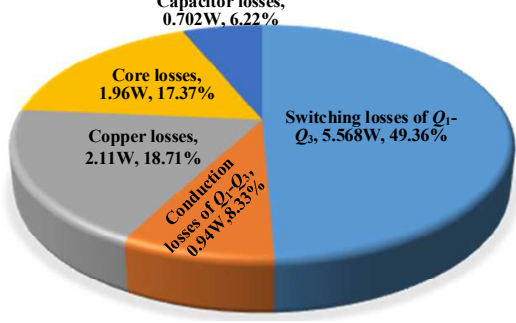

(b) Step-down mode. 
Fig. 23 Calculated power loss distributions for the experiment when $U_{\text {low }}=120 \mathrm{~V}$, $U_{\text {high }}=240 \mathrm{~V}, P_{\mathrm{o}}=300 \mathrm{~W}$ and $d_{\text {Boost }}=1-d_{\text {Buck }}=0.33$.

\section{CONCLUSION}

A non-isolated switched-quasi-Z-source DC-DC converter for electric vehicles with the hybrid energy sources has been proposed in this paper, which is based on the traditional quasi-Z-source bidirectional DC-DC converter. The proposed converter benefits from a wide voltage gain range in step-up and step-down modes and an absolute common ground. In addition, the bidirectional converter has a simple structure with three active power switches, and their voltage stress is lower. The proposed converter also has good dynamic and static performance. Therefore, it can be applied as the power interface between the low voltage battery pack/super capacitor bank and the high voltage DC bus in the hybrid energy sources system for EVs.

\section{REFERENCES}

[1] K. W. Hu, and C. M. Liaw, "Incorporated Operation Control of DC Microgrid and Electric Vehicle," IEEE Trans. Ind. Electron., vol.63, no. 1, pp. 202-215, Jan. 2016.

[2] M. Yilmaz and P. Krein, "Review of benefits and challenges of vehicleto-grid technology," in Proc. IEEE Energy Convers. Congr. Expo., Raleigh, NC, USA, Sep. 2012, pp. 3082-3089.

[3] M. Kesler, M. C. Kisacikoglu, and L. M. Tolbert, "Vehicle-to-grid reactive power operation using plug-in electric vehicle bidirectional offboard charger," IEEE Trans. Ind. Electron., vol. 61, no. 12, pp. 6778-6784, Dec. 2014.

[4] Y. Xue, L. Chang, S. B. Kjaer, J. Bordonau, and T. Shimizu, "Topologies of single-phase inverters for small distributed power generators: An overview," IEEE Trans. Power Electron., vol. 19, no. 5, pp. 1305-1314, Sep. 2004.

[5] M. N. Marwali and A. Keyhani, "Control of distributed generation systems-Part I: voltages and current control," IEEE Trans. Power Electron., vol. 19, no. 6, pp. 1541-1550, Nov. 2004.

[6] M. Yilmaz and P. T. Krein, "Review of battery charger topologies, charging power levels, and infrastructure for plug-in electric and hybrid vehicles," IEEE Trans. Power. Electron., vol. 28, no. 5, pp. 2151-2169, May. 2013.

[7] C. Liu, K. T. Chau, D. Wu, and S. Gao, "Opportunities and challenges of vehicle-to-home, vehicle-to-vehicle, and vehicle-to-grid technologies," Proc. IEEE, vol. 101, no. 11, pp. 2409-2427, Nov. 2013.

[8] M. Choi, S. Kim, and S. Seo, "Energy management optimization in a battery/supercapacitor hybrid energy storage system," IEEE Trans. Smart Grid, vol. 3, no. 1, pp. 463-472, Mar. 2012.

[9] Y. Zhang, Z. Jiang, and X. Yu, "Control strategies for battery/supercapacitor hybrid energy storage systems," in Proc. IEEE Energy 2030 Conf., Nov. 2008, pp. 1-6

[10] K. Jin, M. Yang, X. Ruan, and M. Xu, "Three-level bidirectional converter for fuel-cell/battery hybrid power system," IEEE Trans. Ind. Electron., vol. 57, no. 6, pp. 1976-1986, Jun. 2010.

[11] P. J. Grbovic, P. Delarue, P. Le Moigne, and P. Bartholomeus, "A bi-directional three-level dc-dc converter for the ultra-capacitor applications," IEEE Trans. Ind. Electron., vol. 57, no. 10, pp. 3415-3430, Oct. 2010.

[12] S. Busquets-Monge, S. Alepuz, and J. Bordonau, "A novel bidirectional multilevel boost-buck dc-dc converter," IEEE Trans. Power Electron., vol. 26, no. 8, pp. 2172-2183, Aug. 2011.

[13] I.-D. Kim, S.-H. Paeng, J.-W. Ahn, E.-C. Nho, and J.-S. Ko, "New bidirectional ZVS PWM Sepic/Zeta DC-DC converter," in Proc. IEEE ISIE Conf. Rec., 2007, pp. 555-560.

[14] C. Li, L. Herrera, J. Jia, L. Fu, A. Isurin, A. Cook, Y. Huang and J. Wang, "Design and implementation of a bidirectional isolated Cuk converter for low-voltage and high-current automotive DC source applications," IEEE Trans. Veh. Technol., vol. 63, no. 6, pp. 2567-2577, Jul. 2014.

[15] H.-Y. Lee, T.-J. Liang, J.-F. Chen, and K.-H. Chen, "Design and implementation of a bidirectional SEPIC-Zeta DC-DC Converter," in Proc.
IEEE International Symposium on Circuits and Systems (ISCAS)., pp. 101-104, 2014.

[16] Y.-P. Hsieh, J.-F. Chen, L.-S. Yang, C.-Y. Wu, and W.-S. Liu, "High conversion-ratio bidirectional DC-DC converter with coupled inductor," IEEE Trans. Ind. Electron., vol. 61, no. 1, pp. 210-222, Jan. 2014.

[17] L. Jiang, X. Zhang, C. Yin, C. Mi, S. Li, and M. Zhang, "A novel soft-switching bidirectional dc-dc converter with coupled inductors," IEEE Trans. Ind. Appl., vol. 49, no. 6, pp. 2730-2740, Nov./Dec. 2013.

[18] H Wu, K Sun, L Chen, and L Zhu, "High step-up/step-down soft-switching bidirectional DC-DC converter with coupled-inductor and voltage matching control for energy storage systems," IEEE Trans. Ind. Electron., vol. 63, no. 5, pp. 2892-2903, May. 2016.

[19] H Shen, B Zhang, D Qiu, and L Zhou, "A common grounded Z-source DC-DC converter with high voltage gain," IEEE Trans. Ind. Electron., vol. 63 , no. 5 , pp. 2925-2935, Jan. 2016

[20] G. Zhang, Z. Li, B. Zhang, D. Qiu, W. Xiao, and W. A. Halang, "A Z-source half-bridge converter," IEEE Trans. Ind. Electron., vol. 61, no. 3, pp. 1269-1279, Mar. 2014.

[21] T. Takiguchi and H. Koizumi, "Quasi-Z-source dc-dc converter with voltage-lift technique," in Proc. IEEE 39th Annu. Conf. Ind. Electron. Soc., Nov. 10-13, 2013, pp. 1191-1196.

[22] Y. Tang, T. Wang, and Y. He, "A switched-capacitor-based active-network converter with high voltage gain," IEEE Trans. Power Electron., vol. 29, no. 6, pp. 2959-2968, Jun. 2014.

[23] Y. Tang, D. Fu, T. Wang, and Z. Xu, "Hybrid switched-inductor converters for high step-up conversion," IEEE Trans. Ind. Electron., vol. 62, no. 3, pp. 1480-1490, Mar. 2015.

[24] Y. Tang, T. Wang, and D. Fu, "Multicell switched-inductor/switched -capacitor combined active-network converters," IEEE Trans. Power Electron., vol. 30, no. 4, pp. 2063-2072, Apr. 2015.

[25] H Ardi, A Ajami, F Kardan, SN Avilagh, "Analysis and implementation of a no-isolated bidirectional DC-DC converter with high voltage gain," IEEE Trans. Power Electron., vol. 63, no. 8, pp.4878-4888, Aug. 2016.

[26] Y. S. Lee and Y. P. Ko, "Switched-capacitor bi-directional converter performance comparison with and without quasi-resonant zero-current switching," IET Power Electron., vol. 3, no. 2, pp. 269-278, Mar. 2010.

[27] O. Cornea, GD. Andreescu, N. Muntean, and D. Hulea, "Bidirectional power flow control in a DC microgrid through a switched-capacitor cell hybrid DC-DC converter," IEEE Trans. Ind. Electron., vol. 64, no. 4, pp. 3012-3022, Apr. 2017.

[28] L. S. Yang and T. J. Liang, "Analysis and implementation of a novel bidirectional dc-dc converter," IEEE Trans. Ind. Electron., vol. 59, no. 1, pp. 422-434, Jan. 2012.

[29] X. Fang and X. Ji, "Bidirectional power flow Z-source dc-dc converter," in Proc. IEEE Veh. Power Propulsion Conf. (VPPC'08), pp.1-5.

[30] X. Fang, "A novel Z-source dc-dc converter," in Proc. IEEE ICIT, 2008, pp. $1-4$.

[31] S. Busquets-Monge, S. Alepuz, and J. Bordonau, "A bidirectional multilevel boost-buck dc-dc converter," IEEE Trans. Power Electron., vol. 26, no. 8, pp. 2172-2183, Aug. 2011.

[32] A. Ahmad, RK. Singh, R. Mahanty, "Bidirectional quadratic converter for wide voltage conversion ratio," in Proc. IEEE Int. Conf. PEDES, 2016, pp. 1-5.

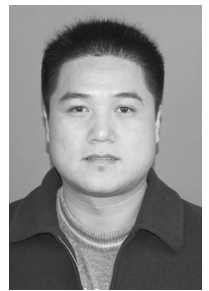

Yun Zhang (M'13) was born in Jiangsu, China, in 1980. He received the B.S. and M.S. degrees in electrical engineering from the Harbin University of Science and Technology, Harbin, China, in 2003 and 2006, respectively, and the Ph.D. degree in electrical engineering from the Harbin Institute of Technology, Harbin, China, in 2010 .

In 2010, he joined the Tianjin University, Tianjin, China, as a Lecturer in the School of Electrical and Information Engineering, where he is currently an Associate Professor. His current research interests include topologies, modulation, and control strategies of power converters for electric vehicles and microgrids. 
Dr. Zhang is an Associate Editor of the Journal of Power Electronics.

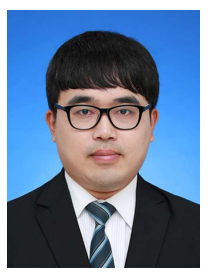

Qiangqiang Liu was born in Jiangsu, China. He received his B.S. degree in Electrical Engineering from the China University of Mining and Technology, Xuzhou, Jiangsu, China, in 2016. He started pursing his M.S. degree in Electrical Engineering from the Tianjin University, Tianjin, China, in 2016.

His current research interests include topologies, modulation, and control strategies of DC-DC converters.

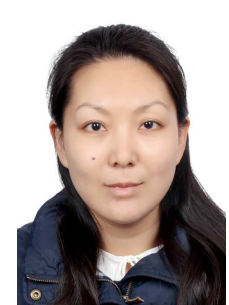

Jing Li (M'15) received the B.Eng. (Hons.) and M.Sc. (Distinction) degrees both in control science and engineering from the Beijing Institute of Technology, Beijing, China, in 1999, and 2002, respectively, and the $\mathrm{Ph} . \mathrm{D}$. degree in electrical engineering from the University of Nottingham, Nottingham, U.K., in 2010.

She was a Research Fellow with the Power Electronic, Machine and Control Group, University of Nottingham. She is currently a Lecturer at the Department of Electrical and Electronic Engineering, University of Nottingham Ningbo China, Ningbo, China. Her research interests include condition monitoring for motor drive systems and power distribution systems and advanced control and design of motor drive systems.

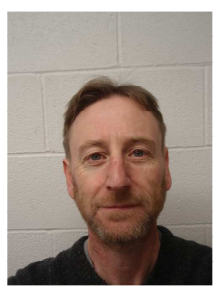

Mark Sumner (SM'05) received the B.Eng. degree in electrical and electronic engineering from Leeds University, Leeds, U.K., in 1986, and the Ph.D. degree in induction motor drives from the University of Nottingham, Nottingham, U.K., in 1992.

He was with Rolls Royce, Ltd., Ansty, U.K. He was a Research Assistant with the University of Nottingham, where he became a Lecturer in October 1992, and is currently a Professor of electrical energy systems. His research interests include control of power electronic systems including sensorlessmotor drives, diagnostics and prognostics for drive systems, power electronics for enhanced power quality, and novel power system fault location strategies. 